\title{
MEDICAL TREATMENT V SURGERY: WHERE DOES MEDICAL TREATMENT END AND SURGERY BEGIN IN TERMS OF SECTION 129 OF THE CHILDREN'S ACT?
}

\section{Introduction}

It has been firmly established in South African law that informed consent prior to the commencement of any form of medical procedure is required by the patient, or proxy decision maker. This principle has been established in South African law by two cases, namely Stoffberg $v$ Elliott (1923 CPD 148) and Castell $v$ De Greeff (1994 (4) SA 408 (C)). If the necessary consent is not obtained, the doctor may, among others, incur liability for civil or criminal assault (Carstens and Pearmain Foundational Principles of South African Medical Law (2007) 890).

Initially, consent to the medical treatment of minors was regulated by the Child Care Act (74 of 1983). In terms of section 39(4) of this Act, a minor who reached the age of 18 years was legally competent to consent to an operation while a minor over the age of 14 could independently consent to medical treatment. (This would include a termination of pregnancy, inclusive of an anaesthetic. See Van Oosten "Choice on Termination of Pregnancy Act: Some Comments" 1999 SALJ 67. A termination of pregnancy is performed in terms of the Choice on Termination of Pregnancy Act (92 of 1996) and not the Children's Act (38 of 2005), therefore it will not be discussed in this note). Van Oosten also notes that neither the terms "medical treatment" nor "operation" are defined in the Child Care Act. (Van Oosten 1999 SALJ 67 fn 41).

The Child Care Act prescribed a cumbersome procedure that had to be followed if the parent or guardian of a child needed to consent to an operation or medical treatment and the responsible person could not be found, could not consent by reason of mental incapacity, refused to consent or was deceased. In such cases the medical practitioner had to report the matter to the Minister of Social Development who could then give proxy consent (s 39(1) of the Child Care Act). In the case of an emergency when an operation or treatment was necessary to save the life of a minor or prevent serious physical injury and a competent person could not be found to consent, the superintendent of the hospital could consent to the necessary procedure (s 39(2) of the Child Care Act). Concerns were raised that the process was cumbersome, led to delays and was therefore not in the interest of minors who need immediate access to medical treatment (Karpelowsky and Rode "Medical Consent for a Minor - An Alternative Proposal" 2006 SAMJ 508). 
As will be pointed out below, the terms "medical treatment" or "surgery" have also not been defined in the Children's Act. (Schäfer Child Law in South Africa: Domestic and International Perspectives (2011) 195). This note therefore seeks to find a workable solution to address the issue of where medical treatment ends and surgery begins as this has an effect on the consent requirements for these procedures. Finally, recommendations will be made based on the research. To put it in context, the consent requirement in the Children's Act will be discussed, followed by definitions of medical treatment and surgery as well as the way in which other jurisdictions treated the issue of medical treatment and surgery.

\section{Consent to medical treatment or surgery in terms of the Children's Act 38 of 2005}

The Child Care Act was repealed and replaced by the Children's Act. The Children's Act prescribes two requirements that have to be met for valid consent by the minor for his or her own medical treatment or surgery. Firstly, the age requirement has to be met and secondly there is the maturity requirement (Kassan and Mahery "Special Child Protective Measures in the Children's Act" in Boezaart (ed) Child Law in South Africa (2009) 208). These requirements will be dealt with in detail below.

In terms of the provisions of section 129 of the Children's Act, there are different criteria regarding consent to medical treatment and surgery. Section 129(2) provides that a child who is older than 12 years of age may independently consent to his or her own medical treatment - or the medical treatment of his or her child - provided that the child is of sufficient maturity and has the mental capacity to understand the benefits, risks, social and other implications of the treatment (the maturity test). In terms of section 129(3) a child who is older than 12 years may consent to a surgical operation on him or her - or the surgery of his or her child - if the child passes the maturity test. In the case of surgery, there is the additional requirement that a child over the age of 12 years but below the age of 18 years must be duly assisted by his or her parent or guardian. Regulations 48 and 49 provide that consent must be given in writing by both the person performing the operation, or a representative of the institution where the operation will be performed, as well as the child on whom the operation will be performed. If the minor is assisted by a parent or guardian, the latter must also give consent in writing on the prescribed form. Likewise, a caregiver may consent to the medical treatment of a child who is older than 12 (but younger than 18 years), but not surgery. This is an improvement on the Child Care Act that had no such provision (Kassan and Mahery in Boezaart Child Law in South Africa 209-210).

Section 129(4) of the Children's Act has a further provision namely that a parent, guardian or caregiver may consent to medical treatment if a child is under the age of 12 years (Schäfer Child Law in South Africa: Domestic and International Perspectives 195-196), or over the age of 12 years and does not meet the maturity requirement (Schäfer Child Law in South Africa: Domestic and International Perspectives 199-197). 
Section 129 of the Children's Act should be read together with section 31 of the Children's Act, which deals with major decisions involving the child. A healthcare decision (s 31(1)(b)(iv)) is a major decision involving the child. Subsection 1(a) provides that the child's age, maturity and stage of development and the view of the child must be considered when a major decision regarding the child is taken. This gives effect to the principle that a child's development is not a static condition, but that children become more mature as they grow older as well as the fact that some children may be able to take serious healthcare decisions at an earlier age than their counterparts (Ngwena "Health Care Decision-making and the Competent Minor: The Limits of Self-determination" in Keightley (ed) Children's Rights (1996) 132133.) Children are given greater autonomy concerning their health care as they grow older and become more mature. This is underpinned by section 10 of the Children's Act. In terms of this section, a child that is old enough and mature enough to participate in a matter concerning him or her should be able to "participate in an appropriate way and views expressed by the child must be given due consideration".

The best interests of the child have to be considered whenever any decision regarding a child, including medical treatment, has to be made. There has been a move away from the common-law position where parents had complete autonomy over the child to the best interests of the child standard enunciated in section 28(2) of the Constitution of the Republic of South Africa, 1996. ("A child's best interests are of paramount importance in every matter concerning the child"). This is echoed in section 9 of the Children's Act. ("In all matters concerning the care, protection and well-being of a child the standard that the child's best interest is of paramount importance, must be applied"). The focus is now more on the best interests of the child and not so much on the interests of the parent. Consequently, this standard has had an impact on consent to medical treatment and surgery on minors as the best interests of the child has to be taken into consideration when any decision regarding medical treatment or an operation on a minor has to be made.

After receiving and considering comments on their first issue paper (Issue Paper 13, Project 110, First Issue Paper (18 April 1998)), the South African Law Reform Commission explained in their follow-up report why it was decided to lower the age of consent to medical treatment to 12 years. (Project 110 (December 2002) 139-140. See also Kassan and Mahery in Boezaart Child Law in South Africa 208-209). They stated that one of the reasons was that the procedure prescribed by the Child Care Act, where the Minister had to give consent, was impractical. After due consideration was given to the comments received after their initial report, it was felt that a child above 12 years and below 18 years of age and who passed the maturity test, could consent to medical treatment (Project 110 (Dec 2002) 142). It should be noted that no maturity test was prescribed by the Child Care Act (Schäfer Child Law in South Africa: Domestic and International Perspectives 195-196).

The Children's Act also provides for alternative decision-makers: In the case of an emergency where treatment is necessary to preserve or save the life of the minor and cannot be deferred, the superintendent of the hospital 
may give consent to treatment or surgery (s 129(6); Kassan and Mahery in Boezaart Child Law in South Africa 210-211; Schäfer Child Law in South Africa: Domestic and International Perspectives 197). When the parent or guardian withholds his or her consent, cannot consent or cannot be traced, the Minister of Social Development can also give consent to medical treatment or surgery (s 129(7) and (8); Kassan and Mahery in Boezaart Child Law in South Africa 211-212). Regulation 47 prescribes that this must be done in writing and on the prescribed form. Finally, the High Court or Children's Court can also be requested to step in and give consent if a person who is authorised to give consent refuses to give consent or cannot be found (s 129(9); Kassan and Mahery in Boezaart Child Law in South Africa 212; Schäfer Child Law in South Africa: Domestic and International Perspectives 197-198).

In their first issue paper, the South African Law Reform Commission duly posed the question whether the concepts "operation" and "medical treatment" needed to be defined (Issue Paper 13, Project 110, The Review of the Child Care Act, 108. See also Schäfer Child Law in South Africa: Domestic and International Perspectives 195). However, it seems that these questions were left unanswered in the follow up report and eventually in the Children's Act.

\section{Surgery versus medical treatment (Definitions)}

As early as 1917 surgeons tried to give a definition of surgery. In a letter to Earl, Lewis Pilcher gave the following definition of major surgery: "[m]ajor surgery includes all work requiring a general anaesthetic; all operations which involve opening into the great cavities of the body; all operations in the course of which hazards of severe haemorrhage are possible; all conditions in which the life of the patient is at stake; all conditions which require for their relief manipulations for the proper performance of which special anatomical knowledge and manipulative skill are essential." (Earl "Definition of Major and Minor Surgery: A Question and an Answer" 1917 Annals of Surgery 799). However, one should bear in mind that in 1917 aggressive medical treatment with possible serious side-effects such as chemotherapy did not exist.

Dorland's Medical Dictionary also does not shed light on what surgery entails. The definition provided for the term "surgery" reads as follows, "that branch of medicine which treats diseases, injuries, and deformities by manual or operative methods" (Dorland's Illustrated Medical Dictionary (1985) sv 1278). Likewise, it does not offer a satisfactory definition for the term "treatment", which reads as follows, "the management and care of a patient for the purpose of combating disease or disorder" (Dorland's Illustrated Medical Dictionary sv 1388). There is also a definition for "operation": "1. any act performed with instruments or by the hands of a surgeon; a surgical procedure. 2. Any effect produced by an agent employed in therapy" (Dorland's Illustrated Medical Dictionary sv 924). It is interesting that different definitions for "operation" and "surgery" are given. When all these definitions are read together it seems as though all three terms would fall under the wider definition of "medical treatment". The Collins Dictionary provides a more workable definition of "surgery" namely "medical treatment 
in which a person's body is cut open by a surgeon in order to treat or remove the problem part" (Collins English Dictionary (2005) sv 834). This definition supposes that surgery is a form of medical treatment which entails that some form of incision is made into the body. The definition of the term "treatment" reads as follows, "the medical or surgical care given to a patient" (Collins English Dictionary sv 890).

If consideration is given to the dictionary definitions of "treatment" and "surgery" it would seem as though "treatment" is a broader term that encompasses both "surgery" and "treatment".

Loftus, Nel and Maartens ("Toestemming Deur Minderjariges: Die Grys Area Tussen Operasie en Mediese Behandeling" 1994 De Rebus 486) also mention that the legislator has thus far failed to give an indication of what should be regarded as "medical treatment" and "surgery" in terms of section 39(4) of the Child Care Act. They point out that any surgical procedure that is performed under a general anaesthetic is generally regarded as "surgery" while the oral administration of medication is deemed "medical treatment". However, they rightly point out that there is a grey area between these two (Loftus et al 1994 De Rebus 486). These authors list certain procedures that should be treated as "surgery", namely (1) Any surgical procedure that is performed under general or local anaesthetic for therapeutic and/or diagnostic purposes. (2) Any procedure that entails the taking of tissue (excluding blood) by way of a needle or other instrument (Loftus et al 1994 De Rebus 486). A laparotomy, insertion of sutures in skin wounds, open reduction of a fracture or dislocation and the insertion of a drainage tube are likewise seen as surgery (Loftus et al 1994 De Rebus 486). Included under the definition of "surgery" is any procedure which involves the taking of tissue, excluding blood, by means of a needle or other surgical instrument, such as a liver biopsy and an aspiration of a renal cyst (Loftus et al 1994 De Rebus 486-487). Procedures that can be classified as "medical treatment" include the administering of any medical substance (including blood products) orally, intravenously or in any other way (Loftus et al $1994 \mathrm{De}$ Rebus 487). These authors recommend that parental consent is obtained for potentially dangerous procedures such as radiotherapy and chemotherapy, while the child's wishes are also honoured, before any aggressive medical treatment with potentially serious side effects, such as radiotherapy or chemotherapy, is given (Loftus et al 1994 De Rebus 487). Regarding dental procedures, the filling of a cavity is considered to be medical treatment, while the extraction of a tooth should be regarded as surgery (Loftus et al 1994 De Rebus 487).

According to Sloth-Nielsen "[medical treatment] is understood to include all procedures other than those requiring surgical intervention." (SlothNielsen "Protection of Children" in Davel and Skelton (eds) Commentary on the Children's Act (2007, revised in 2013) 63). This is an over-simplification of what medical treatment and surgery entail and leaves us with more questions than answers. There are certain forms of medical treatment, such as chemotherapy and radiotherapy that is more invasive and which potentially have more serious side effects than certain forms of surgery, for example having a mole removed or a tooth extracted. This proves that the 
distinction between the terms "surgery" and "medical treatment" can sometimes be very complex as the discussion below illustrates.

Although the legal issues in the case that will be discussed below dealt with informed consent, it highlights the fact that radiotherapy which is classified as medical treatment, can be more dangerous than surgery. In casu a child received radiotherapy on more than one occasion (Esterhuizen $v$ Administrator Transvaal 1957 (3) SA 710 (T)). Initially, she received radiotherapy treatment for a small nodule below the right ankle. However, more nodules appeared and she was in and out of the hospital for about ten times between 1945 and 1949. Eventually she received deep radiotherapy treatment on both her feet and legs to approximately the knees, and both hands were treated up to the wrists. Eventually both her legs and two fingers on her left hand had to be amputated. This was necessitated by postradiation malignant ulcers.

\section{$4 \quad$ English and Welsh law}

It has proven useful to consider the law of England and Wales as consent to medical treatment has been dealt with in the Family Reform Act, 1969. Moreover, the Gillick competence was introduced by the Courts in England and Wales and this test has since been applied by other jurisdictions, even outside England and Wales.

Initially, doctors considered parents to be the surrogate decision makers for their children's healthcare needs. The enactment of the Family Reform Act changed the position and children are now given more autonomy to make their own decisions regarding medical treatment and surgery commensurate to their age (Fortin Children's Rights and the Developing Law (2009) 147. See also MacDonald The Rights of the Child: Law and Practice (2011) 233-235).

The Family Reform Act not only lowered the age of majority from 21 years to 18 years (s $1(1)$ ), but section 8 also deals specifically with consent to medical treatment. In terms of section 8(1) a person who has reached the age of 16 years (but who is still below 18 years of age) may independently consent to any surgical, medical or dental treatment. No parental consent is needed for any of these procedures for a child aged 16 or 17 years. Section 8(2) gives an umbrella definition of "surgical, medical or dental treatment", namely "any procedure undertaken for the purposes of diagnosis, and this section applies to any procedure (including, in particular, the administration of an anaesthetic) which is ancillary to any treatment as it applies to that treatment."

Consent may also be given by a person who does not have parental responsibility for a particular child, but in whose care the child is. Such a person may do what is reasonable in the circumstances to safeguard and promote the child's welfare (s 3(5) of the Children Act, 1989).

The British Medical Association (BMA) states that age is not necessarily the overriding factor for valid consent to medical treatment. However, they advise that parental consent (or consent from someone with parental responsibility) should also be obtained in the case of serious or risky 
procedures especially where the mental capacity of the minor can be questioned (British Medical Association Consent, Rights and Choices in Health Care for Children and Young People (2001) 15). The BMA, however, does not mention what is to be considered as "serious or risky intervention". This is presumably left to the discretion of the doctor(s). Moreover, the BMA emphasises that the opinion of the child should be considered when decisions regarding their healthcare are taken and that the child is provided with sufficient information in order to make an informed decision (Levy et al Consent, Rights and Choices in Health Care for Children and Young People 5-6).

The Gillick case was a landmark decision regarding consent to medical treatment of minors. The Gillick saga started when the Department of Health and Social Security (DHSS) issued guidance on family planning for young people within the NHS. In terms of this circular a doctor could in exceptional circumstances lawfully prescribe contraceptives to girls below the age of 16 without parental consent (Gillick $v$ West Norfolk and Wisbech Area Health Authority [1985] 3 All ER 402; [1986] 1 FLR 229; [1986] AC 112. See also Fortin Children's Rights and the Developing Law 147-150; Harper Medical Treatment and the Law: The Protection of Adults and Minors in the Family Division (1999) 86-87; Ngwena in Keightley Children's Rights 141-142; Pilcher "Contrary to Gillick: British Children and Sexual Rights since 1985" 1997 The International Journal of Children's Rights 300-301). Victoria Gillick, a mother of under-aged daughters, was heavily opposed to this and wanted assurance that she would be informed if one of her daughters sought such advice without her prior knowledge and consent until they were 16. This resulted in her approaching the court to provide assurance that the provision of treatment, provision of contraceptives and abortion advice without her consent to any of her daughters will be unlawful. The court of first instance held that a child who could understand the treatment could lawfully consent to such treatment. However, Mrs Gillick decided to appeal this decision. The Court of Appeal held in favour of Mrs Gillick. The DHSS then appealed to the House of Lords. The House of Lords held that the original advice circulated by the Department of Health was not unlawful (Gillick v West Norfolk and Wisbech Area Health Authority [1986] AC 112. See also Brazier and Cave Medicine, Patients and the Law (2011) 447; Hagger The Child as Vulnerable Patient. Protection and Empowerment (2009) 28). The Court further held that a child below the age of 16 years may be given medical advice and treatment without prior parental consent, provided that the child has "sufficient understanding and intelligence to enable him or her to understand fully what is proposed" (Gillick $v$ West Norfolk and Wisbech Area Health Authority [1986] AC 112, [1986] per Lord Scarman 189 par 27; Brazier and Cave Medicine, Patients and the Law 448; Levy et al Consent, Rights and Choices in Health Care for Children and Young People 34-35). This is where the so-called Gillick competence test originated. By using the age of 16 the House of Lords followed the provisions in the Family Reform Act.

This case was praised for the fact that it respected children's rights and the autonomy of children to make their own decisions regarding medical treatment (Hagger The Child as Vulnerable Patient. Protection and Empowerment 28; Jones "Adolescent Gender Identity and the Courts" in 
Freeman Children's Health and Children's Rights (2006) 121; Sanci, Sawyer, Weller, Bond and Patton "Youth Health Research Ethics: Time for a Mature Minor Clause?" 2004 Med J Aust 2). Harper notes that "[i]t is a question of fact in each case whether a child seeking advice" on contraceptives, abortion or medical treatment is of sufficient maturity to understand fully what is proposed (Harper Medical Treatment and the Law: The Protection of Adults and Minors in the Family Division 86). Someone with parental responsibility cannot veto a child's decision to undergo medical treatment if the child is Gillick competent, only a court may do so (Harper Medical Treatment and the Law: The Protection of Adults and Minors in the Family Division 87). The problem with the Gillick competence test is that it is a subjective test and it is not easy to determine when a particular child is Gillick competent. There are no hard and fast rules to determine whether a minor is Gillick competent, but each case should be assessed individually. (Fortin Children's Rights and the Developing Law 151).

The Gillick competence test takes cognisance of the fact that childhood is not a static condition and that children mature as they grow older and reach the age of majority. In the same manner, their autonomy to consent to medical treatment (and not only reproductive decisions) increases. (See also Levy et al Consent, Rights and Choices in Health Care for Children and Young People 28 and Ngwena in Keightley Children's Rights 133; Pilcher 1997 The International Journal of Children's Rights 314). The competence to make decisions is not so much dependant on the age of the child, but rather on the subjective features of the child in respect of a particular medical treatment (Jones in Freeman Children's Health and Children's Rights 129). Skegg is of the opinion that many children under the age of 10 would be able to consent to "minor and straightforward medical procedures", but the same cannot be said of major procedures (Skegg "Consent to Medical Procedures on Minors" 1973 Modern LR 373). However, the author does not indicate what would constitute "minor and straightforward procedures" and "major procedures".

The Gillick competence test is echoed in the legislation of different jurisdictions, such as the Children's Act (38 of 2005) and certain jurisdictions in Australia.

\section{The legal position in Australia (Victoria, New South Wales and South Australia)}

Three jurisdictions in Australia, namely Victoria, New South Wales and South Australia, offer a workable solution for the difference between medical treatment and surgery. These jurisdictions give definitions for medical treatment and surgery. These will be investigated as they deal with consent to the medical treatment and surgery of those incapable of doing so themselves.

In Victoria the Guardianship and Administration Act, 1986 and the Medical Treatment Act, 1988 deal with people who are unable to make their own decisions regarding medical treatment and where a surrogate decision maker is needed. Although both these Acts give guidance regarding consent to medical treatment to people over the age of 18 years, but who are unable 
to make their own health care decisions, there are valuable lessons to be learnt regarding the consent requirement for minors as well, especially since medical treatment is defined in the Act.

The Guardianship and Administration Act 1986 (Act No 58 of 1986, hereinafter " $G$ and A Act") gives a definition for both medical and dental treatment in section 3 . Medical treatment is broadly defined as any medical treatment which includes a medical or surgical procedure, operation or examination as well as prophylactic, palliative or rehabilitative treatment performed by or under supervision of a registered practitioner. Dental treatment is defined in similar terms, namely a procedure, operation or examination normally carried out by or under the supervision of a registered practitioner ( $G$ and A Act, s 3 ). A number of procedures are excluded from the definition of medical treatment, namely: (i) a special procedure (this is defined as (a) any treatment that could render the person on whom it is carried out, infertile, or (b) a procedure carried out for research or (c) terminate a pregnancy or (d) the removal of tissue for transplantation or medical or dental treatment that is prescribed by the regulations as a special procedure); (ii) a non-intrusive examination made for diagnostic purposes; (iii) first-aid treatment; (iv) the administration of a pharmaceutical drug according to prescription or, if it is a drug for which no prescription is required, according to the manufacturer's instructions and (e) any other kind of treatment set out in the regulations ( $G$ and $A$ Act, s 3 ). In terms of this Act, a registered practitioner may perform emergency medical treatment without consent in the following cases: (a) to save the patient's life; (b) to prevent serious damage to the patient's health or (c) to prevent the patient from suffering or continuing to suffer significant pain or distress ( $G$ and A Act, $s$ $42 \mathrm{~A}(1))$.

In terms of the $G$ and $A$ Act a medical practitioner may perform medical treatment without consent in an emergency under specific circumstances, namely to save the patient's life, to prevent serious damage to the patient's health, or to prevent the patient to suffer or to continue suffering significant pain or distress (s $42 \mathrm{~A}(1)$ ). A medical practitioner may also perform medical or dental treatment without consent if he or she believes that such treatment will be in the best interests of the patient. This may be done provided that the practitioner cannot find the substitute decision maker for the patient and has given notice to the Public Advocate (s 42K(1) and (2)).

A further definition of "medical treatment" is found in The Medical Treatment Act, 1998 (41 of 1988) which defines "medical treatment" in broad terms as the carrying out of an operation, or the administration of a drug or any other medical procedure, excluding palliative care (s 3 ). Palliative care is defined in the Act as including: "(a) the provision of reasonable medical procedures for the relief of pain, suffering and discomfort; or (b) the reasonable provision of food and water". This has led the Supreme Court of Australia to rule on the distinction between medical treatment and palliative care. In Re BWV; Ex parte Gardner (2003) 7 VR 487; [2003] VSC 173 the court was requested to intervene and decide whether the provision of nutrition and hydration via a percutaneous endoscopic gastrostomy (PEG) was to be regarded as medical treatment in terms of the term "medical treatment" in the Medical Treatment Act. This Act provides that a guardian 
can refuse medical treatment on behalf of a patient, but not palliative care (par 10). See also Mendelsohn and Ashby "The Medical Provision of Hydration and Nutrition: Two very Different Outcomes in Victoria and Florida" 2004 Journal of Law and Medicine 283). The court also gave its view of what should be regarded as "medical treatment: "a medical procedure can generally be described as a procedure that is based upon the science of the diagnosis, treatment or prevention of disease or injury, or of the relief of pain, suffering and discomfort. It is not a simple matter to say what is and what is not a medical procedure. Some procedures, such as bloodletting, might once have been regarded as medical procedures but may no longer be regarded as such" (par 75). The court concludes that the administration of artificial nutrition and hydration via a PEG cannot be regarded as palliative care within the meaning of the Medical Treatment Act (par 103).

In New South Wales a parent or guardian can consent to the medical treatment of a child younger than 16 years. This is provided in section 49(1) of the Minors (Property and Contracts) Act (Act No 60 of 1970). However, in terms of section 49(2) a minor who is already 14 years of age may also independently consent to his or her own medical or dental treatment. In both cases, the consent has the same effect as though the minor was 21 years of age and giving consent himself or herself (the age of majority was lowered after the commencement of this Act). Section 49 gives a definition for both medical and dental treatment in subsection (4):

"dental treatment means:

(a) treatment by a dentist in the course of the practice of dentistry, or

(b) treatment by any person pursuant to directions given in the course of the practice of dentistry by a dentist.

medical treatment means:

(a) treatment by a medical practitioner in the course of the practice of medicine or surgery, or

(b) treatment by any person pursuant to directions given in the course of the practice of medicine or surgery by a medical practitioner."

In New South Wales a doctor may perform minor medical procedures without consent if the medical practitioner or dentist who performs the treatment or supervises the treatment deems the treatment necessary and urgent (a) to save the patient's life; (b) to prevent serious damage to the patient's health, or (c) to prevent the patient from suffering or continuing to suffer significant pain or distress. The latter does not apply in the case of special treatment (Guardianship Act, 1987 No 257 [NSW] s 37). A set of regulations set out which forms of treatment are to be regarded as special medical treatment, major medical treatment and major dental treatment respectively. Any treatment that will result in the termination of pregnancy, a vasectomy or tubal occlusion as well as any aversive stimulus is regarded as "special treatment" (Guardianship Regulation 2016 Part 3, reg 9). Regulation 10 provides an extensive list of medical procedures that will be regarded as "major medical treatment". Regulation 11 set out which procedures are to be treated as "major dental treatment". (For lack of space these will not be listed here). 
The Consent to Medical Treatment and Palliative Care Act (South Australia) gives a broad definition of medical treatment. The definition includes physical, surgical or psychological treatment, as well as the prescription of drugs. In terms of this Act a minor of 16 years and over can consent to medical treatment "as validly and effectively as an adult" (Part 2, Division 1, s 6). It further provides that when two medical practitioners are of the opinion and state in writing that a specific treatment is in the best interests of the child and the child is "capable of understanding the nature, consequences and risks" involved, that child can validly consent to his or her own treatment even before the child is 16 years of age (Division 4, s 12). The Gillick competence test is therefore also used in South Australia.

\section{Conclusion}

In both the Child Care Act and the Children's Act a distinction is drawn between the consent requirements for medical treatment and surgery. Although it was pointed out by van Oosten, Loftus, Nel and Maartens and the Law Reform Commission that no definition for either of these concepts was given in the Child Care Act, this was not addressed in the Children's Act.

The Children's Act not only lowers the age at which a minor can consent to medical treatment, but also gives parents, guardians and even caregivers the authority to consent to the medical treatment of a minor. In the case of surgery, a caregiver cannot consent and a minor older than 12 years and younger than 18 years needs the assistance of a parent or guardian. In cases where the age at which a minor can consent to all medical procedures is lower than the age of majority, but above 12 years, the Gillick competence test is applied to determine whether the minor is mature enough to be able to give consent to medical treatment. However, neither medical treatment nor surgery has been defined in the Children's Act nor its predecessor, the Child Care Act. It has proven useful to look at legislation in other jurisdictions for workable solutions to differentiate between these two terms.

The Family Reform Act in England and Wales lowers the age at which a minor may consent to any form of medical treatment (including surgery) without prior parental consent to 16 years. This Act includes surgical, medical or dental treatment in one broad definition. This makes sense as children older than 16 years and younger than 18 in England and Wales can consent to all forms of medical treatment. It is therefore not necessary to draw a distinction between treatment and surgery.

In Australia (Victoria) medical and surgical procedures are included in one term, namely "medical treatment". It is important that the procedure must be performed by a registered practitioner. "Dental treatment" is not included in the definition of "medical or surgical procedures" and has its own separate definition.

In New South Wales the parents of a minor younger than 16 years need to consent to any form of medical and dental treatment. What is significant is that a more comprehensive definition of "medical treatment" and "dental treatment" is given in s 49 of the Minors (Property and Contracts) Act, although it should be noted that both definitions include treatment as well as 
surgery. The Guardianship Act (NSW) has a set of Regulations that lists those procedures that should be regarded as "major medical treatment", "major dental treatment" and "special treatment".

If one considers the dictionary definitions of medical treatment it seems that "medical treatment" should rather be used as an umbrella term that includes both medical and dental treatment, as well as surgery.

Thus far there are no decided cases on section 129 of the Children's Act to give guidance on how the terms "medical treatment" and "surgery" should be interpreted. It is recommended that the Children's Act be amended and that the legislation in Victoria and New South Wales be followed by including separate definitions for "medical treatment" and "dental treatment" in the Act.

Furthermore, the consent requirements should also be revised to make provision for consent to major and minor medical treatment. A distinction should be drawn between major and minor medical treatment. A list of what constitutes major and minor medical treatment should be drafted in collaboration with medical specialists. This list should be included in the Regulations that accompany the Children's Act. A minor who is older than 12 years should be able to consent to minor treatment without assistance by a parent, guardian or caregiver. Such a minor should be assisted by a parent or guardian (or even a caregiver if a parent cannot be found, or is deceased) to consent to major treatment. On the other hand, a parent, guardian or caregiver should consent to any form of treatment of a minor who is younger than 12 years, or older than 12 years, but lacking the mental capacity to consent to treatment.

These recommended amendments to the Children's Act will address the "grey area" between medical treatment and surgery that was identified by Loftus, Nel and Maartens as well as the South African Law Reform Commission.

Carina van der Westhuizen University of South Africa (UNISA) 